\title{
Isolation and characterization of antagonistic Paenibacillus polymyxa HX-140 and its biocontrol potential against Fusarium wilt of cucumber seedlings
}

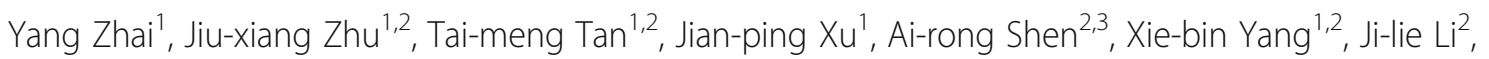
Liang-bin Zeng ${ }^{1 *}$ and Lin Wei ${ }^{4^{*}}$

\begin{abstract}
Objective: The aim of this study is to evaluate the efficacy of the strain Paenibacillus polymyxa HX-140, isolated from the rhizosphere soil of rape, to control Fusarium wilt of cucumber seedlings caused by Fusarium oxysporum $\mathrm{f}$. sp. cucumerinum.

Results: Strain HX-140 was able to produce protease, cellulase, $\beta-1,3$-glucanase and antifungal volatile organic compounds. An in vitro dual culture test showed that strain HX-140 exhibited broad spectrum antifungal activity against soil-borne plant pathogenic fungi. Strain HX-140 also reduced the infection of Fusarium wilt of cucumber seedlings by $55.6 \%$ in a greenhouse pot experiment. A field plot experiment confirmed the biocontrol effects and further revealed that antifungal activity was positively correlated with inoculum size by the root-irrigation method. Here, inoculums at $10^{6} 10^{7}$ and $10^{8} \mathrm{cfu} / \mathrm{mL}$ of $\mathrm{HX}-140$ bacterial suspension reduced the incidence of Fusarium wilt of cucumber seedling by $19.5,41.1$, and $50.9 \%$, respectively.
\end{abstract}

Conclusions: Taken together, our results suggest that P. polymyxa HX-140 has significant potential in the control of Fusarium wilt and possibly other fungal diseases of cucumber.

Keywords: Fusarium wilt, Cucumber, Paenibacillus polymyxa, Antagonistic bacterium, Biocontrol mechanism

\section{Background}

Cucumber is an economically important and popular vegetable crop. Vascular wilt of cucumber caused by $\mathrm{Fu}$ sarium oxysporum f. sp. cucumerinum J. H. Owen (FOC) is one of the most destructive soil-borne diseases that causes large economic losses on a worldwide scale [33]. Pathogens of the Fusarium genus have an extremely broad host range including cotton, tomato, banana,

\footnotetext{
* Correspondence: zengliangbin@caas.cn; nkyweilin@163.com 'Institute of Bast Fiber Crops, Chinese Academy of Agricultural Sciences, No.348 Xianjiahu West Road, Changsha 410205, Hunan, China ${ }^{4}$ Institute of Plant Protection, Hunan Academy of Agricultural Sciences, No.726 Yuanda 2nd Road, Changsha 410125, Hunan, China Full list of author information is available at the end of the article
}

strawberry, potato, capsicum, beans, peas, chickpea, and melons, and are among the most harmful soil-borne pathogens in crop production systems. They usually infect plants through the roots, causing damping-off, root rot, and vascular wilt $[9,44]$.

Chemical control using fungicides has been the most common control strategy for managing diseases caused by Fusarium spp. However, their extensive usage has not only caused negative environmental and toxicological impact but has also jeopardized human and animal health [44]. Furthermore, the application of chemical fungicides is known to select for resistant strains which limits their long-term effectiveness [19, 28]. Therefore,

(c) The Author(s). 2021 Open Access This article is licensed under a Creative Commons Attribution 4.0 International License, which permits use, sharing, adaptation, distribution and reproduction in any medium or format, as long as you give appropriate credit to the original author(s) and the source, provide a link to the Creative Commons licence, and indicate if changes were made. The images or other third party material in this article are included in the article's Creative Commons licence, unless indicated otherwise in a credit line to the material. If material is not included in the article's Creative Commons licence and your intended use is not permitted by statutory regulation or exceeds the permitted use, you will need to obtain permission directly from the copyright holder. To view a copy of this licence, visit http://creativecommons.org/licenses/by/4.0/ The Creative Commons Public Domain Dedication waiver (http://creativecommons.org/publicdomain/zero/1.0/) applies to the data made available in this article, unless otherwise stated in a credit line to the data. 
efficient and safe methods to prevent and control diseases caused by Fusarium wilt are urgently needed.

Biological control is an ecologically friendly, sustainable, and safe method for the control of plant infections. Biocontrol is a reliable alternative to the use of chemical fungicides [15]. Specifically, biocontrol of Fusarium wilts via bacterial antagonists has been extensively studied. For example, Bacillus subtilis SQR9 was found to control Fusarium wilt of cucumber by colonizing plant roots and producing lipopeptides (fengycin and bacillomycin) that were effective against $F$. oxysporum [8]. B. velezensis RC 218 reduced disease severity of Fusarium head blight (FHB) caused by Fusarium graminearum and reduced the accumulation of the associated mycotoxins [31]. "Amfissis" trees treated with Paenibacillus Alvei K165 exhibited significantly lower disease severity and lower relative AUDPC (Area Under the Disease Progress Curve) values than those of un-treated, diseased plants [27]. Streptomyces griseorubens E44G was found to possess chitinolytic activity and was capable of decreasing the severity of Fusarium wilt of tomato and increasing the growth and yield of tomato [35]. Lastly, isolates of the fungus Trichoderma asperellum that exhibited high levels of chitinase and $\beta-1,3$-glucanase activities strongly inhibited the mycelia growth of F. oxysporum f. sp. Lycopersici [14].

In the context of the current study, the bacterium Paenibacillus polymyxa has shown strong inhibitory effects against pathogenic nematodes, oomycetes, and fungi, including F. oxysporum. This biocontrol agent was reported to produce antifungal peptides, volatiles, proteins, and other antimicrobial substances that inhibit fungal pathogen mycelial growth. Several studies have revealed multiple mechanisms of anti-fungal activities, including competition for nutrients, the production of antifungal compounds such as antibiotics, extracellular enzymes, and organic volatiles [16] and the induction of plant resistance.

In this study, an antagonistic bacterium (P. polymyxa isolate HX-140) with antagonistic effects on FOC and other phytopathogenic fungi was identified, and its potential mechanism and control effect of Fusarium wilt disease were also explored.

\section{Results}

\section{Screening and characterization of HX-140 strain}

A total of 76 bacterial isolates showing inhibitory activities against $F$. oxysporum were isolated from the rhizosphere soil samples of rape, pepper and flax (Table 1). Among them, preliminary tests show that 23 strains showed antagonistic effects against four pathogens (Rhizoctonia solani Kuhn, Phytophthora capsici Leon., Sclerotinia sclerotiorum Lib., and Fusarium oxysporum Schl.). In this paper, HX-140 was taken as an example to study the biological control mechanism and the effect of HX-140 on cucumber Fusarium wilt control (Fig. 1).

Based on DNA sequence of the 16S rDNA gene of strain HX-140 (GenBank accession number MF136611), this strain was revealed to be most similar to $P$. polymyxa. When strain HX-140 was cultured on a NA plate it appeared as small, milky white, opaque colonies with irregular edges. The bulged surface appeared smooth and moist (Fig. 2). Gram staining showed that the strain HX-140 was a rod-shaped, Gram-negative bacterium (Figure S1, see Supplemental materials.).

Compared to the type strain of Paenibacillus (P. polymyxa ATCC $842^{\mathrm{T}}$ ), strain HX-140 exhibited almost identical physiological characteristics, except for a variation in nitrate reduction. Strain HX-140 and P. polymyxa ATCC $842^{\mathrm{T}}$ are both positive for growing in 3\% $\mathrm{NaCl}(\mathrm{w} / \mathrm{v})$, anaerobic growth, starch hydrolysis, casein hydrolysis, the VP (Voges-Proskauer) test, and acid production using galactose, ${ }_{\mathrm{L}}$-arabinose, $\mathrm{D}$-fructose, and $\mathrm{D}$-xylose. However, HX-140 was negative for indole production and unable to use citrate (Table 2).

Based on the combined morphological, physiological, and molecular characterizations (Fig. 3), strain HX-140 was identified as $P$. polymyxa.

\section{Evaluation the antifungal activity of $\mathrm{HX}-140$ and its associated antifungal compounds}

The antifungal activity of $P$. polymyxa HX-140 on tested pathogens was greater than $60 \%$ and had an optimal efficacy of $79.2 \%$ against $F$. oxysporum (Table 3), suggesting that HX-140 is a broad-spectrum antagonistic bacterium with biocontrol potential.

P. polymyxa HX-140 created clear zones around colonies on the skim-milk agar, CMC, and Aniline blue agar media (Fig. 4), indicating that $P$. polymyxa HX-140 exhibited extracellular protease, cellulase and $\beta-1,3$-glucanase activities, respectively. This was not observed on the chitin-agar, indicating the absence of chitinase activity.

In the sealed plate assays, $P$. polymyxa HX-140 exhibited a significant inhibition of the growth of $F$. oxysporum mycelia compared with that in the control group (Fig. 5), indicating that $P$. polymyxa HX-140 was able to produce anti-fungal volatiles.

\section{Control effect of strain HX-140 on cucumber Fusarium wilt in the greenhouse and field \\ Pot experiment}

The biocontrol efficacy of HX-140 was studied with both pot and field experiments. The symptoms of Fusarium wilt appeared 18 days after inoculation with $F$. oxysporum. Strain HX-140 had a positive effect in controlling Fusarium wilt of cucumber in this experiment. The disease index of the T, CK1 and CK2 treatment groups 
Table 176 strains with antagonistic effect on FOC, and their isolated sources

\begin{tabular}{|c|c|c|c|c|c|}
\hline Number & $\begin{array}{l}\text { Rhizoctonia solani } \\
\text { Kuhn }\end{array}$ & $\begin{array}{l}\text { Phytophthora capsici } \\
\text { Leon. }\end{array}$ & $\begin{array}{l}\text { Sclerotinia sclerotiorum } \\
\text { Lib. }\end{array}$ & $\begin{array}{l}\text { Fusarium oxysporum } \\
\text { Schl. }\end{array}$ & Rhizosphere soil sources \\
\hline $\mathrm{HX}-35$ & - & $* * *$ & - & $*$ & Flax \\
\hline$H X-37$ & $* * *$ & $* * *$ & $* *$ & $* *$ & Pepper \\
\hline$H X-42$ & $* * *$ & * & $* * *$ & $* * *$ & Pepper \\
\hline$H X-50$ & $* *$ & $* *$ & * & $* *$ & Pepper \\
\hline$H X-51$ & $* *$ & $* *$ & * & $* *$ & Pepper \\
\hline$H X-53$ & $* *$ & $* * *$ & - & $* *$ & Pepper \\
\hline$H X-54$ & - & - & - & $* *$ & Pepper \\
\hline$H X-60$ & $* *$ & - & $* * *$ & $* *$ & Rape \\
\hline$H X-61$ & - & - & * & * & Rape \\
\hline$H X-62$ & - & - & $* *$ & $* * *$ & Rape \\
\hline$H X-63$ & - & - & - & $* *$ & Rape \\
\hline$H X-64$ & - & - & - & * & Rape \\
\hline$H X-65$ & - & * & - & * & Rape \\
\hline$H X-69$ & - & * & - & * & Rape \\
\hline $\mathrm{HX}-70$ & $* * *$ & $* * *$ & - & * & Rape \\
\hline$H X-71$ & - & * & - & * & Rape \\
\hline$H X-72$ & $* * *$ & $* * *$ & $* * *$ & $* *$ & Rape \\
\hline$H X-73$ & $* * *$ & $* *$ & $* * *$ & * & Rape \\
\hline HX-88 & $* *$ & $* *$ & * & * & Rape \\
\hline HX-89 & * & $* * *$ & - & * & Rape \\
\hline$H X-91$ & * & * & - & * & Pepper \\
\hline HX-92 & $* * *$ & $* * *$ & $* * *$ & * & Pepper \\
\hline HX-94 & - & - & - & * & Pepper \\
\hline HX-99 & * & * & - & * & Flax \\
\hline$H X-100$ & * & $* *$ & - & * & Flax \\
\hline$H X-101$ & - & $* *$ & - & * & Flax \\
\hline HX-105 & - & - & - & $*$ & Rape \\
\hline HX-107 & * & $* *$ & $* *$ & * & Rape \\
\hline$H X-110$ & $* *$ & - & - & $* *$ & Pepper \\
\hline$H X-111$ & $* *$ & - & - & $* *$ & Pepper \\
\hline$H X-112$ & - & - & - & $* *$ & Pepper \\
\hline$H X-113$ & - & - & - & $* *$ & Pepper \\
\hline$H X-115$ & $* *$ & - & - & * & Pepper \\
\hline$H X-116$ & $* *$ & - & - & * & Pepper \\
\hline$H X-121$ & $* * *$ & $* *$ & $* *$ & * & Flax \\
\hline$H X-122$ & $* *$ & - & - & * & Flax \\
\hline$H X-123$ & $* *$ & * & $* *$ & $* *$ & Flax \\
\hline$H X-124$ & $* *$ & * & $* *$ & * & Flax \\
\hline$H X-125$ & $* * *$ & $* *$ & $* * *$ & * & Flax \\
\hline$H X-126$ & $* *$ & $* *$ & $* *$ & * & Flax \\
\hline$H X-128$ & $* *$ & $*$ & $* *$ & $* *$ & Flax \\
\hline$H X-129$ & $* *$ & - & * & * & Flax \\
\hline$H X-130$ & * & - & * & * & Flax \\
\hline
\end{tabular}


Table 176 strains with antagonistic effect on FOC, and their isolated sources (Continued)

\begin{tabular}{|c|c|c|c|c|c|}
\hline Number & $\begin{array}{l}\text { Rhizoctonia solani } \\
\text { Kuhn }\end{array}$ & $\begin{array}{l}\text { Phytophthora capsici } \\
\text { Leon. }\end{array}$ & $\begin{array}{l}\text { Sclerotinia sclerotiorum } \\
\text { Lib. }\end{array}$ & $\begin{array}{l}\text { Fusarium oxysporum } \\
\text { Schl. }\end{array}$ & Rhizosphere soil sources \\
\hline HX-131 & * & - & - & * & Flax \\
\hline$H X-133$ & * & $* *$ & - & * & Flax \\
\hline$H X-134$ & * & - & * & * & Flax \\
\hline$H X-135$ & $* *$ & - & * & * & Flax \\
\hline$H X-136$ & $* * *$ & - & $* * *$ & $* *$ & Flax \\
\hline$H X-137$ & $* * *$ & $* *$ & $* *$ & * & Flax \\
\hline$H X-138$ & $* * *$ & - & - & * & Flax \\
\hline$H X-139$ & - & - & $* *$ & * & Flax \\
\hline$H X-140$ & $* *$ & $* *$ & $* * *$ & $* *$ & Rape \\
\hline$H X-142$ & * & - & * & * & Rape \\
\hline$H X-143$ & $* * *$ & - & * & * & Rape \\
\hline$H X-144$ & - & - & * & * & Flax \\
\hline$H X-145$ & $* *$ & - & - & * & Flax \\
\hline$H X-146$ & * & $* *$ & - & * & Flax \\
\hline$H X-147$ & $* * *$ & $* *$ & - & * & Rape \\
\hline$H X-148$ & $* *$ & - & - & * & Rape \\
\hline$H X-149$ & - & $* *$ & - & * & Rape \\
\hline$H X-161$ & * & $*$ & - & * & Rape \\
\hline HX-162 & * & - & - & * & Rape \\
\hline$H X-163$ & $* *$ & $* *$ & $* *$ & $* *$ & Rape \\
\hline HX-165 & * & $*$ & * & * & Rape \\
\hline$H X-166$ & * & - & $*$ & * & Rape \\
\hline$H X-167$ & $* *$ & $* *$ & * & * & Rape \\
\hline$H X-168$ & * & $* * *$ & $*$ & $* *$ & Rape \\
\hline$H X-169$ & $* *$ & $* *$ & $* *$ & $*$ & Rape \\
\hline$H X-172$ & - & - & - & * & Rape \\
\hline$H X-173$ & - & - & - & * & Rape \\
\hline$H X-179$ & * & - & $* *$ & * & Rape \\
\hline$H X-180$ & $* *$ & - & $* *$ & $* *$ & Flax \\
\hline$H X-181$ & * & - & - & * & Rape \\
\hline HX-182 & * & - & $* *$ & * & Rape \\
\hline HX-184 & $* * *$ & $*$ & $* *$ & * & Pepper \\
\hline$H X-187$ & $* * *$ & * & - & * & Rape \\
\hline
\end{tabular}

-: the bacteriostatic zone diameter is zero; *: The antibacterial zone diameter is greater than 0 and less than 10 mm; **: The diameter of the inhibition zone is greater than or equal to $10 \mathrm{~mm}$, and less than $20 \mathrm{~mm}$; ***: The diameter of the inhibition zone is greater than or equal to $20 \mathrm{~mm}$

was $20,11.5$ and 45 , respectively. The disease index of cucumber seedlings with the $P$. polymyxa HX-140 and $F$. oxysporum treatment $(\mathrm{T})$ was significantly lower than those seedlings with only F. oxysporum (CK2). As expected, the healthiest seedlings were in the negative control with only sterile water (CK1). The infection of Fusarium wilt in cucumber seedlings was significantly $(P<0.05)$ reduced to $35 \%$, and the relative control efficacy was $55.6 \%$ after treatment with $P$. polymyxa HX140 (Table 4).

\section{Field experiment}

Within the field experiment, a small proportion of cucumber seedlings exhibited symptoms of wilting before the inoculation of the HX-140 bacterial suspension. The field site was partitioned into small plots all with similar rates of infected plants and similar disease indices. These small plots were randomized to receive four treatments: CK, T1, T2 and T3 treatment (Table 5). Fourteen days after inoculation with varying concentrations of HX-140 suspensions, the incidence rate and disease index of the 


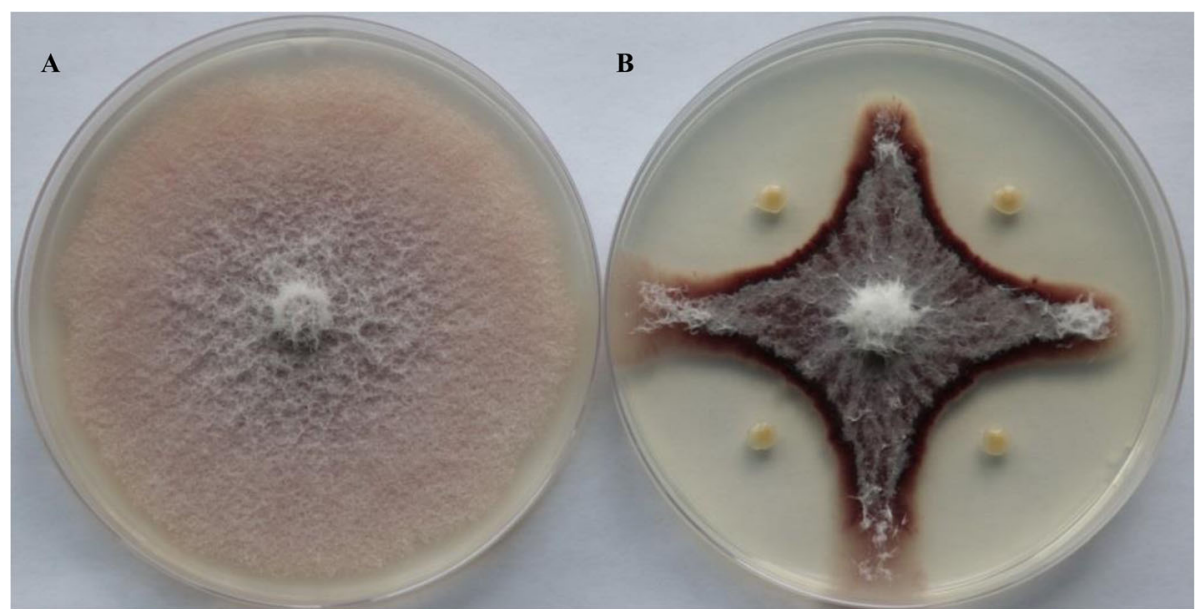

Fig. 1 Antagonistic effect of HX-140 against F. oxysporum. a, the control; b, Co-inoculated

control group was $76.19 \%$ and 59.37 , respectively. The efficacies of different concentrations $\left(10^{6}, 10^{7}\right.$ and $10^{8}$ $\mathrm{cfu} / \mathrm{mL}$ ) of HX-140 bacterial suspension were evaluated and shown to be $19.5,41.1$, and $50.9 \%$, respectively. The control efficacy increased as the concentration of HX140 increased. Likely influenced by a diversity of biotic and abiotic factors in the field, the control efficacy of strain HX-140 in the field was lower than that in the greenhouse pot culture. However, all three treatments (T1, T2, and T3) showed lower disease incidence and lower disease index than those of the control group. These results suggest that $P$. polymyxa HX-140 had a significant suppressive effect on Fusarium wilt of cucumber seedlings in the field with a history of the disease.

\section{Discussion}

In this study, the antifungal activity of $P$. polymyxa HX140 on $F$. oxysporum was tested in vitro prior to a

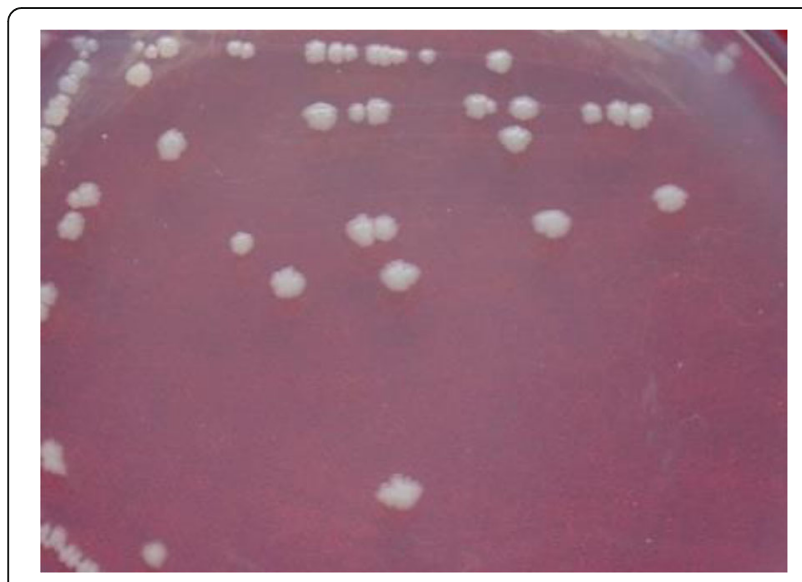

Fig. 2 Colony morphology of strain HX-140 on NA medium greenhouse pot experiment, and $P$. polymyxa HX-140 exhibited antagonistic activity against the tested pathogenic fungi. As determined by the greenhouse pot and the field experiments, P. polymyxa HX-140 significantly decreased the wilt disease of cucumber seedlings caused by FOC. Specifically, biocontrol efficacies of strain HX140 in the greenhouse pot and field experiments were 55.6 and $50.9 \%$, respectively, similar to or higher than several previously reported candidate biocontrol agents. For example, the biocontrol efficacies of Streptomyces albospinus CT205 were reported to be 8.7 and $51.9 \%$ in 2011 and 2012, respectively [39]. In their field experiment, the disease and death incidences were 40.9 and $23.4 \%$ respectively in the CK group, and 31.7 and $15.6 \%$ after treatment with strain CT205, both of which were lower than that identified for HX-140 in this study. However, the biocontrol efficacy of CT205 in its proprietary formulation (BOF-CT205) was higher than HX140 in reducing Fusarium wilt [39]. The high biocontrol efficacy of BOF-CT205 may be related to the specialized supplements within the formulation which may enhance the ability of strain CT205 to grow in the field environment and exert antagonistic effects in the soil. It is also possible that the supplemented nutrients in the biocontrol/bio-organic fertilizer stimulated the growth of $\mathrm{cu}$ cumber roots [39]. Regardless of the potential mechanism (s), the high efficacy of BOF-CT205 suggests several potential avenues for improving the biocontrol effects of strain HX-140 in field applications.

In our study, $P$. polymyxa strain HX-140 was selected due to its high antifungal activity against $F$. oxysporum. In addition, $P$. polymyxa HX-140 displayed a broad spectrum of antifungal activities against six other pathogens. $P$. polymyxa was previously designated to the genus Bacillus and reclassified to the new genus 
Table 2 Physiological and biochemical characterization of strain HX-140

\begin{tabular}{|c|c|c|}
\hline Characteristics & P. polymyxa $\mathrm{HX}-140^{a}$ & P. polymyxa ATCC $842^{\mathrm{Ta}}$ \\
\hline Anaerobic growth & + & + \\
\hline Growth with $3 \% \mathrm{NaCl}$ & + & + \\
\hline Hydrolysis of starch & + & + \\
\hline Hydrolysis of casein & + & + \\
\hline Nitrate reduction & + & $\vee$ \\
\hline Indole production & - & - \\
\hline VP test & + & + \\
\hline Citrate utilization & - & - \\
\hline \multicolumn{3}{|c|}{ Acid production from carbon sources } \\
\hline Galactose & + & + \\
\hline L-Arabinose & + & + \\
\hline D-Fructose & + & + \\
\hline D-Xylose & + & + \\
\hline
\end{tabular}

$a_{+}$Positive reaction, - Negative reaction, $V$ variable

Paenibacillus in 1994 [10]. P. polymyxa strains have been reported as highly effective biocontrol agents for controlling soil borne fungal diseases [26]. For example, Anthracnose symptoms caused by C. gloeosporioides and C. acutatum in harvested apples were suppressed by 83.6 and $79 \%$, respectively, after treatment with $P$. polymyxa APEC128 [23]. P. polymyxa SC09-21 produced cellulase and protease to control P. capsici, and the gene expression levels of pathogenesis-related (PR) proteins, including CaPR4 and CaChi2, were also enhanced after treatment with the SC09-21 strain [42]. There have been some studies on the application of $P$. polymyxa in the control of $F$. oxysporum. For example, $P$. polymyxa NSY50 can significantly up-regulate the expression level of defense related genes PR1 and PR5 in cucumber roots at the early stages upon challenge with FOC [13], $P$. polymyxa WLY78 can strongly inhibit fusarium wilt of cucumber [25], NSY50 and WLY78 can improve the resistance of cucumber to FOC, and also have direct control effect on FOC. Some P. polymyxa strains were able to inhibit the growth of $F$. oxysporum $\mathrm{f}$. sp. albedinis for a long time in vitro [4]. P. polymyxa SQR-21 systemically affects root exudates of watermelon to decrease the conidial germination of $F$. oxysporum f.sp. niveum [30]. P.

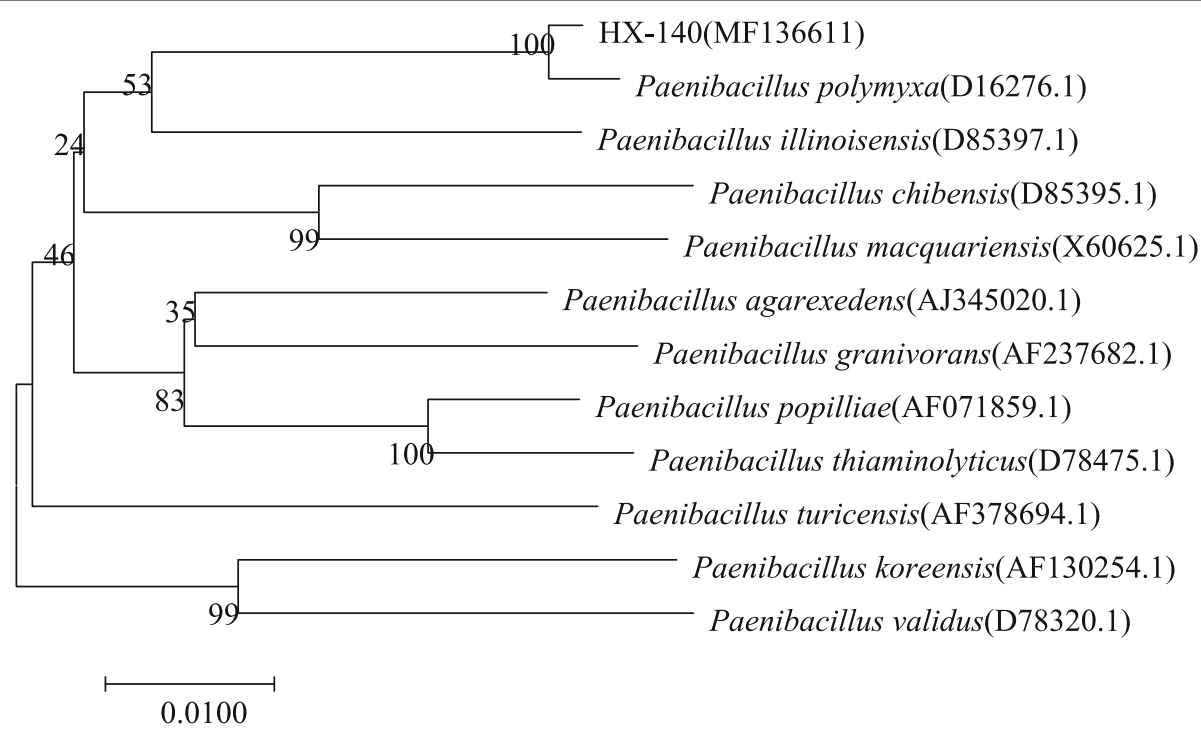

Fig. 3 Phylogenetic analysis based on 16S rDNA sequences of strain HX-140 and closely related species constructed by the neighbor-joining method. The number at the nodes indicates the level of bootstrap support (\%) based on a 1000 replicates. The scale bar at the bottom indicates the genetic distance. GenBank accession numbers analyzed here are shown in parentheses 
Table 3 Antifungal activity of strain HX-140 in dual cultures

\begin{tabular}{lll}
\hline Fungal pathogens & Diameter of the fungal colony in the test group $(\mathbf{m m})^{\mathbf{a}^{\mathbf{2}}}$ & Inhibition rate (\%) $^{\mathbf{b}}$ \\
\hline Fusarium oxysporum Schl. & $18.75 \pm 0.73 \mathrm{e}$ & $79.2 \pm 0.8 \mathrm{a}$ \\
Fusarium lini Boll. & $31.00 \pm 0.38 \mathrm{bc}$ & $65.6 \pm 0.4 \mathrm{~cd}$ \\
Colletotrichum lini West. & $28.63 \pm 0.38 \mathrm{~d}$ & $68.2 \pm 0.4 \mathrm{~b}$ \\
Colletotrichum gloeosporioides Penz. & $29.88 \pm 0.55 \mathrm{~cd}$ & $66.8 \pm 0.6 \mathrm{bc}$ \\
Sclerotinia sclerotiorum Lib. & $31.94 \pm 0.71 \mathrm{~b}$ & $64.5 \pm 0.8 \mathrm{~d}$ \\
Phytophthora capsici Leon. & $34.38 \pm 0.46 \mathrm{a}$ & $61.8 \pm 0.5 \mathrm{e}$ \\
Rhizoctonia solani Kuhn & $30.38 \pm 0.68 \mathrm{bc}$ & $66.3 \pm 0.8 \mathrm{~cd}$ \\
\hline
\end{tabular}

${ }_{\mathrm{a}, \mathrm{b}}$ Data are mean \pm standard error. Different letters are significantly different according to Duncan's multiple range test $(P<0.05)$

polymyxa antagonizes the plant pathogenic fungus $F$. oxysporum in liquid medium by means of an interaction process in which the presence of living bacteria is a prerequisite for continuous suppression of fungal growth [11].

We analyzed the potential contributors to the antifungal activities of $P$. polymyxa HX-140 against Fusarium spp. P. polymyxa HX-140 exhibited strong protease, cellulase and $\beta$-1,3-glucanase activities and produced antifungal VOCs. The fungal cell wall is a dynamic and complex structure. For most fungi, the core of the cell wall is a branched $\beta-1,3$ and $\beta-1,6$ glucan that is linked to chitin via a $\beta-1,4$ linkage. The composition of the cell wall varies markedly between different species of fungi $[2,6,24]$. Protease and $\beta-1,3$-glucanase are both potent enzymes that degrade fungal cell walls [5, 32], while endoglucanases have been shown to cleave internal $\beta-1$, 4-glycosidic bonds [40]. We found that VOCs produced by $P$. polymyxa HX-140 inhibited the mycelial growth of FOC in vitro, which indicates that they may play an important role in the inhibition of soil-borne diseases caused by FOC. The antifungal activity of VOCs has often been an understudied component of research on biocontrol agents, including those of $P$. polymyxa strains [36]. VOCs produced by different biocontrol bacteria operate through varying modalities, such as through the suppression of fungal mycelium growth, the induction of plant systematic resistance, plant growth promotion, and through nematicidal activity $[10,15,21,43]$.

\section{Conclusion}

This study focused on the isolation, identification and characterization of the antagonist activity of the bacterium $P$. polymyxa HX-140 against $F$. oxysporum f. sp. cucumerinum, the causative agent of fusarium wilt on cucumber. Our in vitro analyses showed the antagonistic effect of HX-140 on pathogen growth, including its potent enzymatic activities against fungal pathogens. HX140 was shown to reduce the incidence of cucumber wilt disease in the greenhouse. Furthermore, the bacterium reduced the incidence of cucumber wilt disease by $50.9 \%$ in the field, consistent with its significant application potential in the field. The potential molecular contributors to its antifungal activity as identified here also lay a foundation for further studies of the genes and biochemical pathways of HX-140 to improve its antagonistic efficiency and commercial application in the field.

\section{Methods}

\section{Phytopathogenic strains}

The fungal strains (Fusarium oxysporum, Fusarium lini, Colletotrichum lini, Colletotrichum gloeosporioides, Sclerotinia sclerotiorum, Phytophthora capsici, and Rhizoctonia solani) used in the study were provided by the Key

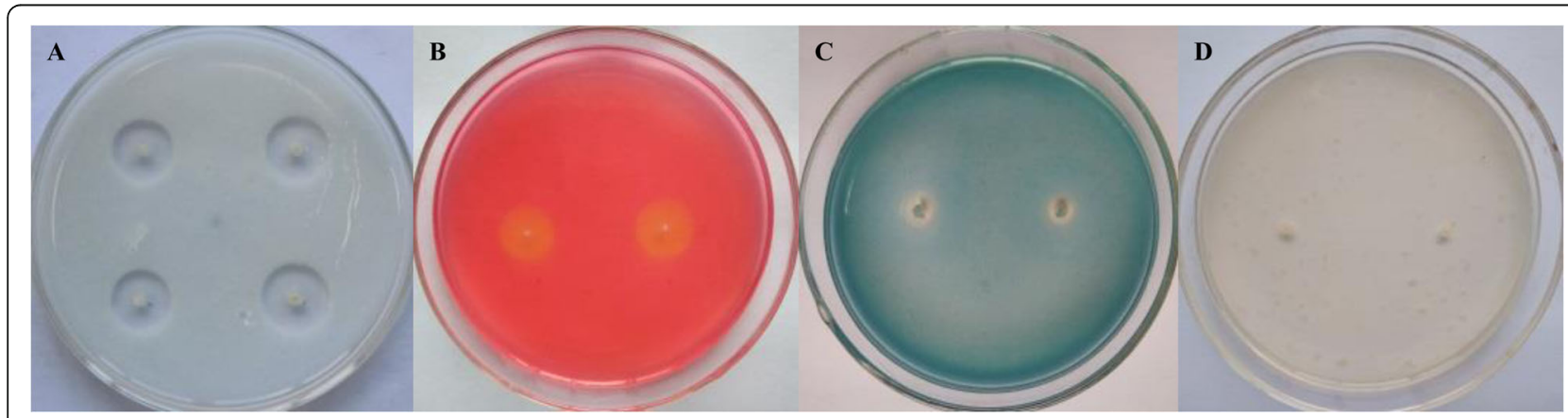

Fig. 4 Detection of antagonist protein production by strain HX-140. a, skim-milk agar medium; b, CMC medium; c, Aniline blue agar medium; $\mathbf{d}$, chitin-agar medium 


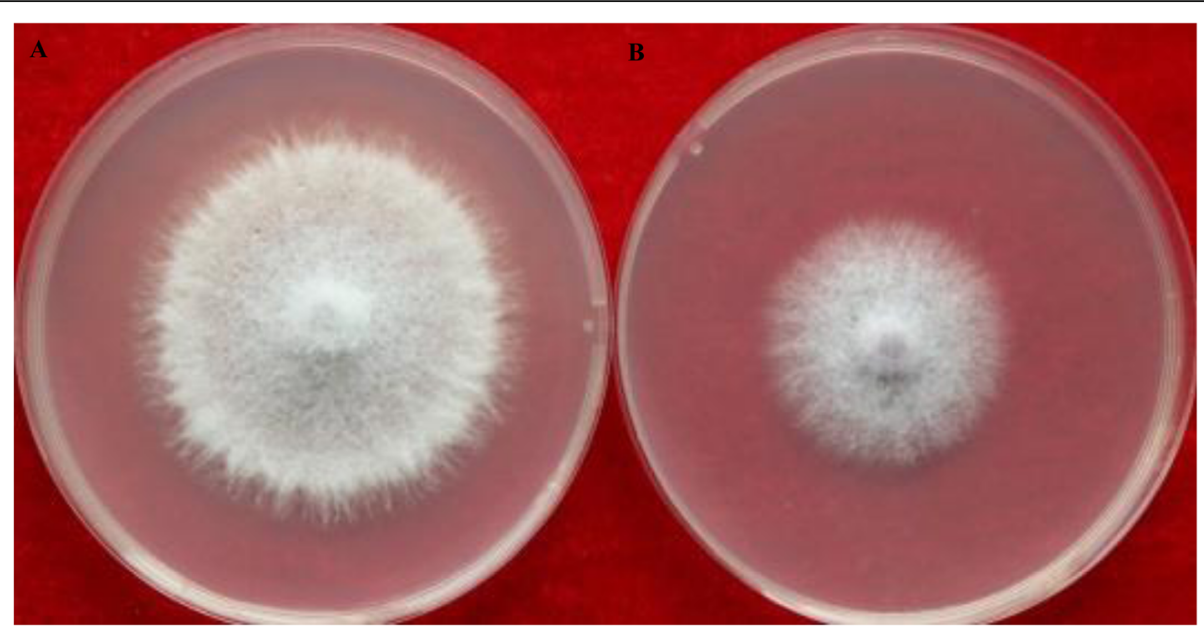

Fig. 5 Detection of antifungal organic volatile compounds from strain HX-140. a, control group; b, test group

Laboratory of Biology and Processing of Bast Fiber Crops, Ministry of Agriculture, Institute of Bast Fiber Crops, Chinese Academy of Agricultural Sciences. and stored at $4{ }^{\circ} \mathrm{C}$ using potato dextrose agar (PDA) medium.

\section{Isolation and screening of antagonistic bacterial strains}

To screen for bacteria with antifungal activities, rhizosphere soil samples of healthy flax and rape crops grown in Gongzhuling City, Jilin Province, China were obtained. The soil samples were suspended and serially diluted 10-fold using sterile water. The diluted suspensions were spread onto Petri plates containing nutrient agar (NA) medium and incubated at $28^{\circ} \mathrm{C}$ for 3 days. Three replicates were performed for each dilution. Bacterial isolates were sub-cultured and purified as single colonies. Representative colonies of different sizes and morphologies were stored on NA slants at $4{ }^{\circ} \mathrm{C}$.

All bacterial isolates were tested for their ability to inhibit fungal growth using the technique of dual culture analysis [13, 45]. Three replicates were used in each treatment and the experiments were repeated twice. In the case of inhibition of $F$. oxysporum f. sp. cucumerinum, the plates were incubated at $28{ }^{\circ} \mathrm{C}$ in the dark and the inhibitory effect on growth was assessed after 9 days.

Table 4 Inhibitory effect of strain HX-140 on cucumber seedling diseases in the greenhouse pot experiment

\begin{tabular}{lllc}
\hline Group & Incidence rate (\%) & Disease index $^{\mathrm{a}}$ & Control efficacy (\%) \\
\hline CK1 & $15.00 \pm 2.89 \mathrm{c}$ & $11.50 \pm 0.61 \mathrm{~b}$ & \\
CK2 & $60.00 \pm 0.00 \mathrm{a}$ & $45.00 \pm 4.62 \mathrm{a}$ & 55.6 \\
T & $35.00 \pm 8.66 \mathrm{~b}$ & $20.00 \pm 5.77 \mathrm{~b}$ &
\end{tabular}

CK1 negative control with only sterile water, CK2 treatment with only $F$. oxysporum, $T$ treatment with both $P$. polymyxa $\mathrm{HX}-140$ and $F$. oxysporum ${ }^{a}$ The lowercase letters in the table indicate significant differences between treatments $(P<0.05)$
The bacterial isolate with the strongest antagonistic effect was selected for further study.

\section{Characterization of strain HX-140 165 rDNA analysis}

Isolate HX-140, a strain with the highest anti-Fusarium oxysporum activity, was obtained from the screening test. In order to taxonomically identify isolate HX-140, its total genomic DNA was extracted using the Bacteria Genomic DNA Kit (CWBIO, Shanghai, China), following the manufacturer's instructions. The $16 \mathrm{~S}$ rDNA was amplified using the universal bacterial primers $27 \mathrm{f}\left(5^{\prime}\right.$ AGAGTTTGATCCTGGCTCAG-3') and 1492r (5' GGTTACCTTGTTACGACTT-3') [38], as described by Rameshkumar and Nair [34]. The amplicon was purified and sequenced by Sangon Biological Engineering Co., Ltd. (Shanghai, China). The DNA sequence was analyzed by comparing with those in NCBI GenBank using the BLAST program [3]. A phylogenetic tree was constructed using the neighbor-joining method [37] with Molecular Evolution Genetics Analysis (MEGA) software version 7.0.

\section{Morphological and physiological features}

The morphological characteristics of strain HX-140 on the NA plate were recorded after incubation at $28^{\circ} \mathrm{C}$ for 3 days.

Physiological tests were performed following the Systematic Determinative Manual of General Bacteria [12]. Gram staining was observed using an Olympus BX53 microscope (Olympus: Tokyo, Japan; software: cellSens Entry 1.8).

\section{Antifungal activity assay}

To assess the potential antifungal effects of HX-140, antagonistic activity against seven phytopathogenic fungi 
Table 5 Inhibitory effect of strain HX-140 on cucumber seedling diseases in the field experiment

\begin{tabular}{|c|c|c|c|c|c|}
\hline \multirow[t]{2}{*}{ Group } & \multicolumn{2}{|c|}{ Before inoculation of $\mathrm{HX}-140$} & \multicolumn{2}{|c|}{ After inoculation of $\mathrm{HX}-140$} & \multirow{2}{*}{$\begin{array}{l}\text { Control } \\
\text { efficacy } \\
(\%)^{\mathrm{a}}\end{array}$} \\
\hline & Incidence rate $(\%)^{a}$ & Disease index $^{a}$ & Incidence rate (\%) ${ }^{a}$ & Disease index $^{a}$ & \\
\hline$\overline{C K}$ & $28.57 \pm 1.03 \mathrm{a}$ & $7.44 \pm 0.68 \mathrm{a}$ & $76.19 \pm 0.60 \mathrm{a}$ & $59.37 \pm 0.45 a$ & \\
\hline $\mathrm{T} 1$ & $27.38 \pm 1.58 \mathrm{a}$ & $7.44 \pm 1.29 \mathrm{a}$ & $68.45 \pm 0.59 b$ & $47.77 \pm 1.12 b$ & 19.5 \\
\hline $\mathrm{T} 2$ & $27.38 \pm 2.15 a$ & $7.44 \pm 1.44 \mathrm{a}$ & $54.76 \pm 1.57 c$ & $34.97 \pm 2.43 c$ & 41.1 \\
\hline T3 & $29.17 \pm 0.60 \mathrm{a}$ & $7.74 \pm 0.52 \mathrm{a}$ & $44.65 \pm 3.72 \mathrm{~d}$ & $30.36 \pm 1.80 c$ & 50.9 \\
\hline
\end{tabular}

CK Control group with no inoculation, $T 1$ treatment with $10^{6} \mathrm{cfu} / \mathrm{mL}$ bacterial suspension of HX-140, $T 2$ treatment with $10^{7} \mathrm{cfu} / \mathrm{mL}, T 3$ treatment with $10^{8} \mathrm{cfu} / \mathrm{mL}$ bacterial suspension of $\mathrm{HX}-140$

a The lowercase letters in the table indicate significant differences between treatments $(P<0.05)$

was assessed on PDA plates by dual culture analysis as described in a previous study [45]. Three replicates were performed for each treatment and the experiments were repeated twice. The plates were incubated for 9 days in the dark at $28{ }^{\circ} \mathrm{C}$ and the antagonism was determined by measuring the zone of inhibition, the distance between the growing edges of HX-140 and fungi. The inhibition ratio was calculated using the following formula [22]:

$$
\begin{aligned}
\text { Inhibition rate }(\%) & =(\text { diameter of fungal colony in control } \\
& - \text { diameter of fungal colony in treatment }) \\
& / \text { diameter of fungal colony in control } \times 100 \% .
\end{aligned}
$$

\section{Analysis of the antifungal compounds of HX-140 against FOC in vitro}

Determination of the production of protease, chitinase, cellulase and $\beta$-1,3-glucanase.

The production of protease by HX-140 was analyzed using the spot inoculation technique [1] on a skim-milk agar medium containing equal volumes of sterilized $4 \%$ solution agar and milk solution [7]. The chitinase production activity of HX-140 was checked on chitin-agar medium containing fine powdered chitin $(0.4 \% \mathrm{w} / \mathrm{v}$ [18]; ). Cellulase activity was assessed on carboxymethyl cellulose (CMC) medium containing $\mathrm{NaNO}_{3} 2 \mathrm{~g}, \mathrm{~K}_{2} \mathrm{HPO}_{4} 1$ g, $\mathrm{MgSO}_{4} \cdot 7 \mathrm{H}_{2} \mathrm{O} 0.5 \mathrm{~g}, \mathrm{KCl} 0.5 \mathrm{~g}, \mathrm{FeSO}_{4} \cdot 7 \mathrm{H}_{2} \mathrm{O} 0.01 \mathrm{~g}$, and agar $16 \mathrm{~g}$ in $1000 \mathrm{ml}$ distilled water at $\mathrm{pH}$ 6.8, supplemented with $1 \% \mathrm{CMC}-\mathrm{Na}$ salt as the carbon source [29]. The activity of $\beta-1,3$-glucanase was detected on aniline blue agar medium [20,32]. Petri plates containing blank skim-milk agar, chitin-agar, CMC, and aniline blue agar mediums were used as controls, respectively. All tests were carried out in triplicate, and the whole experiment was repeated twice. The plates were incubated at $28{ }^{\circ} \mathrm{C}$ for 3 days.

\section{Evaluation the antifungal volatile organic compounds of HX-140}

The production of volatile organic compounds (VOCs) by strain HX-140 was determined using the sealed plate method [16]. Briefly, HX-140 was streaked on NA medium in the cover of a Petri plate and a $5 \mathrm{~mm}$ disk of actively growing $F$. oxysporum mycelia was placed in the center of the PDA medium on the bottom dish. The dish containing the mycelial plug was inverted over the bacterial plate. The dishes were sealed with parafilm. All tests were carried out in triplicate and the experiment was repeated twice. The plates were incubated for 9 days in the dark at $28{ }^{\circ} \mathrm{C}$, and the antagonism was determined by comparing the diameters of $F$. oxysporum colonies in the test groups with the control groups.

\section{Greenhouse pot experiment}

Cucumber seeds (No. 4 Jinchun) were surface-sterilized by immersion in $0.1 \%$ mercuric chloride for $60 \mathrm{~s}$, rinsed in sterile water 3 times, and then stored at $4{ }^{\circ} \mathrm{C}$ overnight to induce germination. Seeds were germinated in a Petri plate incubated with a piece of moist filter paper in the dark at $28{ }^{\circ} \mathrm{C}$ and then sown into the $9 \times 9$-hole seedling pots and covered with approximately $1 \mathrm{~cm}$ of sterilized substrate $\left(121{ }^{\circ} \mathrm{C}\right.$ for $\left.20 \mathrm{~min}\right)$ [13, 46]. Cucumber seedlings were grown in a plant growth chamber at $28{ }^{\circ} \mathrm{C}, 80 \pm 10 \%$ relative humidity, and 12,000 Lux light intensity with a photoperiod of $14 \mathrm{~h}$ light and $10 \mathrm{~h}$ dark.

An actively growing $F$. oxysporum mycelia disk was picked from the margin of the dish and inoculated in PDB (Potato Dextrose Broth) liquid medium. The liquid culture was incubated at $28^{\circ} \mathrm{C}$ for $48 \mathrm{~h}$ on a rotary shaker at $180 \mathrm{r} / \mathrm{min}$ and then diluted to $10^{8} \mathrm{cfu} / \mathrm{mL}$ using PDB for backup. Actively growing cells of strain HX-140 were incubated in Lysogeny broth (LB) medium at $28^{\circ} \mathrm{C}$ for $24 \mathrm{~h}$ at $180 \mathrm{r} / \mathrm{min}$ and then centrifuged at $12000 \mathrm{r} / \mathrm{min}$ for $5 \mathrm{~min}$. The bacteria precipitate was washed three times with sterile water and then diluted to $10^{8} \mathrm{cfu} / \mathrm{mL}$ for downstream use.

The pot experiment was carried out in greenhouse using soil inoculated with $10^{8} \mathrm{cfu} / \mathrm{g}$ microorganisms $(F$. oxysporum spores and/or strain HX-140 cells in $1 \mathrm{~mL}$, representing about $5 \%$ of the weight of soil transplanted with the seedling). Equal volumes of Fusarium liquid culture and HX-140 suspension were mixed with the nutrient soil evenly in the treatment group $(\mathrm{T})$. Control group 1 (CK1) was treated with an equal volume of sterile water, and the control group 2 (CK2) was treated 
with equal volumes of Fusarium liquid culture and sterile water. All treatments were kept at $28^{\circ} \mathrm{C}$ for 2 days to ensure that the Fusarium pathogen (in T and CK2 treatments) and strain HX-140 (in T) antagonist colonized the soil.

For each treatment, twenty cucumber seedlings in the two-leaf stage were planted in the treated nutrient soil. Before planting, their roots were mechanically damaged to help initiate infection. Three replicates were maintained in each treatment and the experiment was repeated twice. The disease severity was investigated 20 days after transplantation of cucumber seedling.

Disease severity of cucumber seedlings was divided into five classes and recorded using a disease index ranging from 0 to 4 as follows:

Level 0-Plant was healthy with no illness;

Level 1-Leaves with slight wilting;

Level 2-Stems and leaves slightly wilted with necrotic spots on the leaves;

Level 3-Plants moderately wilted with necrotic spots on leaves and stems;

Level 4-Plants died.

The disease index and biocontrol efficacy were calculated according to the following formulas [47]:

Incidence rate $=$ the number of diseased plants

/total number of investigated plants $\times 100 \%$

Disease index $=\left[\sum\right.$ (the number of diseased plants in this index

$\times$ disease index $) /($ total plants investigated

$\times$ highest disease index) $] \times 100$.

Biocontrol efficacy $=[$ (disease index of control group 2

- disease index of treatment group)

/disease index of control group 2$] \times 100 \%$.

\section{Field experiment on cucumber seedlings}

The field experiments were carried out on an experimental farm of the Institute of Bast Fiber Crops, Chinese Academy of Agricultural Sciences, in Yuanjiang Country $\left(28^{\circ} 42^{\prime} 26^{\prime \prime} \mathrm{N}, 112^{\circ} 14^{\prime} 37^{\prime \prime}\right.$ E), Hunan Province, China. The total field plot size was $\sim 200 \mathrm{~m}^{2}$, divided into subplots of $1.4 \times 1.6 \mathrm{~m}$. The chosen field for this experiment was planted with cucumber for more than 3 years, and the incidence of cucumber wilt was over $70 \%$. We used a complete randomized block design with three replicates for each treatment. Each sub-plot was planted with 56 seedlings. The experiment was repeated twice from June to November 2018.
The field trial included four treatments: (i) control group with no inoculation (CK); (ii) a treatment group inoculated with $10^{6} \mathrm{cfu} / \mathrm{mL}$ of the $\mathrm{HX}-140$ bacterial suspension (T1); (iii) a treatment group inoculated with $10^{7} \mathrm{cfu} / \mathrm{mL}$ of the $\mathrm{HX}-140$ bacterial suspension (T2); and (iv) a treatment group inoculated with $10^{8} \mathrm{cfu} / \mathrm{mL}$ of the HX-140 bacterial suspension (T3). When the seedlings had 1-2 leaves, $20 \mathrm{~mL}$ of HX-140 bacterial suspension was used to drench their roots. The incidence of cucumber wilt among the different treatments was investigated before HX140 inoculation and 14 days after inoculation.

The disease severity of cucumber seedlings was recorded using a disease index ranging from 0 to 4, identical to the greenhouse pot experiment, and the control efficacy was calculated using the following formulas $[17$, 41]:

$$
\begin{aligned}
\text { Disease index }= & {\left[\sum\right. \text { (the number of diseased plants in this index }} \\
& \times \text { disease index }) /(\text { total plants investigated } \\
& \times \text { highest disease index })] \times 100 .
\end{aligned}
$$

$$
\begin{aligned}
\text { Biocontrol efficacy }= & {[1-(\text { disease index of treatment group after inoculation }} \\
& \times \text { disease index of control group before inoculation }) \\
& /(\text { disease index of treatment group before inoculation } \\
& \times \text { disease index of control group after inoculation })] \\
& \times 100 \% .
\end{aligned}
$$

\section{Statistical analysis}

Statistical analysis was performed using Microsoft Excel 2010 (Microsoft Corporation, Redmond, WA, USA) and DPS 7.05 software (Zhejiang University, Hangzhou, China). Mean values were compared using Duncan's multiple range test with $P<0.05$ as the level of significance.

\section{Supplementary Information}

The online version contains supplementary material available at https://doi. org/10.1186/s12866-021-02131-3.

Additional file 1: Figure S1 Gram staining of strain HX-140. Bar= $20 \mu \mathrm{m}$.

\section{Acknowledgements}

Not applicable.

\section{Authors' contributions}

Zeng $L-B, L i J$ - $L$ and Wei $L$ developed the idea for the study and guided it all the way. Zhu J-X, Tan T-M designed the study, and completed the research with Zhai $Y$, Shen A-R, and Yang X-B. All authors analyzed the data and were involved in writing the manuscript. Xu J-P and Zhai $Y$ finished revising the English manuscript. The author(s) read and approved the final manuscript.

\section{Funding}

This work was supported by the National Key R\&D Program of China (2018YFC0311300), the Major Scientific and Technological Projects of Hunan Province (2016NK1001), the Agricultural Science and Technology Innovation 
Program of the Chinese Academy of Agricultural Sciences (CAAS-ASTIPIBFC07), and the Biology discipline construction funds.

\section{Availability of data and materials}

The datasets generated and/or analysed during the current study are available in the Treebase repository [http://purl.org/phylo/treebase/phylows/ study/TB2:S27431], including a total of 12 sequences, and the evolutionary tree was built based on these sequences. The accession numbers of all sequences in NCBI are: AF071859.1, AF130254.1, AF237682.1, AF378694.1, AJ345020.1, D16276.1, D78320.1, D78475.1, D85395.1, MF136611.1 and X60625.1.

\section{Declarations}

\section{Ethics approval and consent to participate}

Not applicable.

\section{Consent for publication}

Not applicable.

\section{Competing interests}

The authors declare that they have no competing interests.

\section{Author details}

${ }^{1}$ Institute of Bast Fiber Crops, Chinese Academy of Agricultural Sciences, No.348 Xianjiahu West Road, Changsha 410205, Hunan, China. ${ }^{2}$ Hunan Provincial Key Laboratory of Forestry Biotechnology, Central South University of Forestry and Technology, Changsha 410004, China. ${ }^{3}$ Hunan Academy of Forestry, Changsha 410004, China. ${ }^{4}$ Institute of Plant Protection, Hunan Academy of Agricultural Sciences, No.726 Yuanda 2nd Road, Changsha 410125, Hunan, China.

Received: 11 December 2020 Accepted: 9 February 2021 Published online: 06 March 2021

\section{References}

1. Abdallah RAB, Mokni-Tlili S, Nefzi A, Jabnoun-Khiareddine H, Daami-Remadi M. Biocontrol of Fusarium wilt and growth promotion of tomato plants using endophytic bacteria isolated from Nicotiana glauca organs. Biol Control. 2016:97:80-8.

2. Adams DJ. Fungal cell wall chitinases and glucanases. Microbiology. 2004; 150:2029-35.

3. Altschul SF, Gish W, Miller W, Myers EW, Lipman DJ. Basic local alignment search tool. J Mol Biol. 1990;215:403-10.

4. Athmani-Guemouri S. Test of in vitro antagonism of some strains of Paenibacillus polymyxa towards strain of Fusarium oxysporum f. sp. albedinis agent of the fusariose of the date palm. Acta Hortic. 2010;882:963-71.

5. Benítez T, Rincón AM, Limón MC, Codon AC. Biocontrol mechanisms of Trichoderma strains. Int Microbiol. 2004;7:249-60.

6. Bowman SM, Free SJ. The structure and synthesis of the fungal cell wall. Bioessays. 2006:28:799-808

7. Brown MRW. Foster JS. A simple diagnostic milk medium for Pseudomonas aeruginosa. J Clin Pathol. 1970;23:172-7.

8. Cao Y, Zhang Z, Ling N, Yuan Y-J, Zheng X, Shen B, Shen Q-R. Bacillus subtilis SQR 9 can control Fusarium wilt in cucumber by colonizing plant roots. Biol Fertil Soils. 2011;47:495-506.

9. Cha J-Y, Han S, Hong H-J, Cho HJ, Kim D, Kwon Y, Kwon SK, Crüsemann M Lee YB, Kim JF, Giaever G, Nislow C, Moore BS, Thomashow LS, Weller DM Kwak YS. Microbial and biochemical basis of a Fusarium wilt-suppressive soil. IsmeJ. 2016:10:119.

10. Cheng W-L, Yang J-Y, Nie Q-Y, Huang D, Yu C, Zheng L-Y, Cai M-M, Thomashow LS, Weller DM, Yu Z-N, Zhang J-B. Volatile organic compounds from Paenibacillus polymyxa KM2501-1 control Meloidogyne incognita by multiple strategies. Sci Rep-Uk. 2017;7:16213.

11. Dijksterhuis J, Sanders M, Gorris LGM, Smid EJ. Antibiosis plays a role in the context of direct interaction during antagonism of Paenibacillus polymyxa towards Fusarium oxysporum. J Appl Microbiol. 2010;86(1):13-21.

12. Dong $X-Z$, Cai $M-Y$. Identification of common bacteria. In: Lu Y-Y, Liu X-L, editors. Systematic determinative manual of general bacteria. Beijing: Science Press; 2001. p. 353-70.
13. Du N-S, Shi L, Yuan Y-H, Sun J, Shu S, Guo S-R. Isolation of a potential biocontrol agent Paenibacillus polymyxa NSY50 from vinegar waste compost and its induction of host defense responses against Fusarium wilt of cucumber. Microbiol Res. 2017;202:1-10.

14. El Komy MH, Saleh AA, Eranthodi A, Molan YY. Characterization of novel Trichoderma asperellum isolates to select effective biocontrol agents against tomato fusarium wilt. Plant Pathol J. 2015;31(1):50-60.

15. Fernando WGD, Ramarathnam R, Krishnamoorthy AS, Savchuk SC. Identification and use of potential bacterial organic antifungal volatiles in biocontrol. Soil Biol Biochem. 2005;37:955-64.

16. Fiddaman PJ, Rossall S. The production of antifungal volatiles by Bacillus subtilis. J Appl Microbiol. 1993;74:119-26.

17. He L-F, Li X-X, Gao Y-Y, Li B-X, Mu W, Liu F. Oil adjuvants enhance the efficacy of pyraclostrobin in managing cucumber powdery mildew (Podosphaera xanthii) by modifying the affinity of fungicide droplets on diseased leaves. Plant Dis. 2019;103(7):1657-64

18. Hsu SC, Lockwood JL. Powdered chitin agar as a selective medium for enumeration of actinomycetes in water and soil. Appl Microbiol. 1975;29: 422-6.

19. Janga MR, Raoof MA, Ulaganathan K. Effective biocontrol of Fusarium wilt in castor (Ricinius communis L.) with Bacillus sp. in pot experiments. Rhizosphere. 2017:3:50-2

20. Jung HK, Hong J-H, Park SC, Park BK, Nam DH, Kim SD. Production and physicochemical characterization of $\beta$-glucan produced by Paenibacillus polymyxa JB115. Biotechnol Bioproc E. 2007;12:713-9.

21. Kanchiswamy CN, Malnoy M, Maffei ME. Chemical diversity of microbial volatiles and their potential for plant growth and productivity. Front Plant Sci. 2015:6:151.

22. Khedher SB, Kilani-Feki O, Dammak M, Jabnoun-Khiareddine H, DaamiRemadi M, Tounsi S. Efficacy of Bacillus subtilis V26 as a biological control agent against Rhizoctonia solani on potato. CR Biol. 2015;338:784-92.

23. Kim YS, Balaraju K, Jeon Y. Biological control of apple anthracnose by Paenibacillus polymyxa APEC128, an antagonistic rhizobacterium. Plant Pathol J. 2016:32:251.

24. Latgé JP. The cell wall: a carbohydrate Armour for the fungal cell. Mol Microbiol. 2007:66:279-90

25. Li Y-L, Chen S. Fusaricidin produced by Paenibacillus polymyxa wly78 induces systemic resistance against fusarium wilt of cucumber. Int J Mol Sci. 2019;20(20):5240.

26. Ling N, Xue C, Huang Q-W, Yang X-M, Xu Y-C, Shen Q-R. Development of a mode of application of bioorganic fertilizer for improving the biocontrol efficacy to Fusarium wilt. Biocontrol. 2010;55:673-83.

27. Markakis EA, Tjamos SE, Antoniou PP, Paplomatas EJ, Tjamos EC. Biological control of Verticillium wilt of olive by Paenibacillus alvei, strain K165. Biocontrol. 2016;61:293-303.

28. Misra AK, Pandey BK. Pathogenicity and evaluation of fungicides against guava wilt pathogens. J Mycol PI Pathol. 1999;29:274-5.

29. Nayaka S, Vidyasagar GM. Occurrence and extracellular enzyme potential of Actinomycetes of a thermoltalerant, northern region of Karanataka, Inida. Int Multidiscip Res J. 2012;2(12):40-4

30. Ning L, Huang Q, Guo S, Shen Q. Paenibacillus polymyxa sqr-21 systemically affects root exudates of watermelon to decrease the conidial germination of Fusarium oxysporum f.sp. niveum. Plant Soil. 2010;341(1/2):485-493.27.

31. Palazzini JM, Dunlap CA, Bowman MJ, Chulze SN. Bacillus velezensis RC 218 as a biocontrol agent to reduce Fusarium head blight and deoxynivalenol accumulation: genome sequencing and secondary metabolite cluster profiles. Microbiol Res. 2016:192:30-6.

32. Park JK, Kim JD, Park YI, Kim SK. Purification and characterization of a 1, 3- $\beta$ d-glucanase from Streptomyces torulosus PCPOK-0324. Carbohydr Polym. 2012:87:1641-8

33. Qiu M-H, Zhang R-F, Xue C, Zhang S-S, Li S-Q, Zhang N, Shen Q-R. Application of bio-organic fertilizer can control Fusarium wilt of cucumber plants by regulating microbial community of rhizosphere soil. Biol Fertil Soils. 2012:48:807-16.

34. Rameshkumar N, Nair S. Isolation and molecular characterization of genetically diverse antagonistic, diazotrophic red-pigmented vibrios from different mangrove rhizospheres. FEMS Microbiol Ecol. 2009;3(67):455-67.

35. Rashad YM, Al-Askar AA, Ghoneem KM, Saber WI, Hafez EE. Chitinolytic Streptomyces griseorubens $\mathrm{E} 44 \mathrm{G}$ enhances the biocontrol efficacy against Fusarium wilt disease of tomato. Phytoparasitica. 2017:45:227-37. 
36. Raza W, Yuan J, Ling N, Huang Q-W, Shen Q-R. Production of volatile organic compounds by an antagonistic strain Paenibacillus polymyxa WR-2 in the presence of root exudates and organic fertilizer and their antifungal activity against Fusarium oxysporumf. Sp. niveum. Biol Control. 2015;80:8995.

37. Saitou N, Nei M. The neighbor-joining method: a new method for reconstructing phylogenetic trees. Mol Biol Evol. 1987;4:406-25.

38. Tamegai H, Li L, Masui N, Kato C. A denitrifying bacterium from the deep sea at 11000-m depth. Extremophiles. 1997;1:207-11.

39. Wang S, Liang Y, Shen T, Yang H, Shen B. Biological characteristics of Streptomyces albospinus CT205 and its biocontrol potential against cucumber Fusarium wilt. Biocontrol Sci Tech. 2016;26:951-63.

40. Xia T, Li Y-J, Sun D-L, Zhuo T, Fan X-J, Zou H-S. Identification of an extracellular endoglucanase that is required for full virulence in Xanthomonas citri subsp. citri. PLoS One. 2016:11(3):e0151017.

41. Xie X-W, Dong R-L, Shi Y-X, Chai A-L, Zhu F-D, Li J-B. Screening and inhibition effect of antagonistic bacteria against cucumber anthracnose caused by Colletotrichum orbiculare. Chin J Biol Control. 2016;32:215-20.

42. Xu S-J, Kim BS. Evaluation of Paenibacillu spolymyxa strain SC09-21 for biocontrol of Phytophthora blight and growth stimulation in pepper plants. Trop Plant Pathol. 2016;41:162-8.

43. Yang J-W, Kloepper JW, Ryu CM. Rhizosphere bacteria help plants tolerate abiotic stress. Trends Plant Sci. 2009;14:1-4.

44. Yeole GJ, Kotkar HM, Teli NP, Mendki PS. Herbal fungicide to control Fusarium wilt in tomato plants. Biopestic Int. 2016;12:25-35.

45. Yoshida S, Hiradate S, Tsukamoto T, Hatakeda K, Shirata A. Antimicrobial activity of culture filtrate of Bacillus amyloliquefaciens RC-2 isolated from mulberry leaves. Phytopathology. 2001;91:181-7.

46. Zhang M-J, Li J-L, Shen A-R, Tan S-Y, Yan Z, Yu Y-T, Xue Z-D, Tan T-M, Zeng L-B. Isolation and identification of Bacillus amyloliquefaciens IBFCBF-1 with potential for biological control of Phytophthora blight and growth promotion of pepper. J Phytopathol. 2016;164:1012-21.

47. Zheng Y, Xue Q-Y, Xu L-L, Xu Q, Lu S, Gu C. Guo J-H. A screening strategy of fungal biocontrol agents towards Verticillium wilt of cotton. Biol Control. 2011;56:209-16.

\section{Publisher's Note}

Springer Nature remains neutral with regard to jurisdictional claims in published maps and institutional affiliations.

Ready to submit your research? Choose BMC and benefit from:

- fast, convenient online submission

- thorough peer review by experienced researchers in your field

- rapid publication on acceptance

- support for research data, including large and complex data types

- gold Open Access which fosters wider collaboration and increased citations

- maximum visibility for your research: over $100 \mathrm{M}$ website views per year

At $\mathrm{BMC}$, research is always in progress.

Learn more biomedcentral.com/submissions 